\title{
Modelling of Forces Acting on a System of the UAV Launcher, Based on Passive Magnetic Suspensions with Superconductors
}

\author{
Modeliranje sila koje djeluju na sustav UAV \\ lansera, na temelju pasivne magnetske suspenzije sa \\ superprovodnicima
}

\author{
Anna Sibilska-Mroziewicz \\ Warsaw University of Technology \\ Faculty of Mechatronics \\ Poland \\ e-mail:a.sibilska@mchtr.pw.edu.pl
}

\author{
Edyta Ładyżyńska-Kozdraś \\ Warsaw University of Technology \\ Faculty of Mechatronics \\ Poland \\ e-mail: e.ladyzynska@mchtr.pw.edu.pl
}

\author{
Krzysztof Falkowski \\ Military University of Technology \\ Faculty of Mechatronics and Aerospace \\ Poland \\ e-mail: kfalkowski@wat.edu.pl
}

\author{
DOI 10.17818/NM/2020/1.9 \\ UDK $537.6 / .8$ \\ Preliminary communication / Prethodno priopćenje \\ Paper accepted / Rukopis primljen: 4. 8. 2019.
}

\section{Summary}

Modern sea operations used for exploration and reconnaissance purposes are becoming more and more dependent on unmanned air vehicles (UAV). With the development of an increasing number of UAVs directed to the needs of the navy, various take-off and landing systems are being tested. An alternative to the traditionally used catapults is magnetic catapults, which enable continuous power control, properly increasing the acceleration of the starting machine and at the same time enabling full automation of the launching process. The paper presents the developed of the physical model and theoretical analyzes the forces and torques acting on the launcher system using passive magnetic suspensions with high-temperature superconductors. The launcher was modeled as a configuration of three elements: tracks built from neodymium magnets generating the magnetic field, a starting cart driven by a linear engine and a UAV taking off or landing on the launcher cart. The set of assumptions regarding the characteristics of the environment, the structure of the system elements, kinematic constraints were made. The article consists also the theoretical analysis of external interactions having a decisive influence on the dynamics of the system. The analysis considers the couplings resulting from mutual interactions of individual elements of the system. Theoretical considerations were supplemented with a comparative analysis of numerical and experimental studies of the UAV launch process from the launcher which allowed the verification of the key parameters of the analyzed forces.

\section{Sažetak}

Moderne pomorske operacije korištene za eksploataciju i izviđanje na moru postaju sve više ovisne o vozilima bez posade (UAV). Razvojem povećanoga broja UAV-a, koji su usmjereni na potrebe mornarice, testiraju se različiti sustavi polijetanja i slijetanja. Alternativa tradicionalno upotrijebljenim katapultima magnetski je katapult, koji omogućava neprekidnu kontrolu snage, pravilno povećavajući akceleraciju početnoga stroja i istodobno omogućuje potpunu automatizaciju procesa lansiranja. Članak predstavlja razvoj fizičkoga modela i teoretski analizira sile izakretne momente koji djeluju na sustav lansiranja koristeći pasivnu magnetsku suspenziju sa superprovodnicima visoke temperature. Lanser je modeliran kao konfiguracija triju elemenata: trake napravljene od neodimium magneta koji proizvodi magnetsko polje, početnih kola koja pokreće linearni stroj te UAV-a koji polijeće ili slijeće na lansirna kola. Postavljen je set pretpostavki koje se tiču karakteristika okoliša, struktura sustava elemenata $i$ kinematskih ograničenja. Članak se također sastoji od teoretske analize ieksternih interakcija, koje imaju odlučujući utjecaj na dinamiku sustava. Analiza razmatra parove koji rezultiraju iz uzajamnih interakcija individualnih elemenata sustava. Teoretska razmatranja nadopunjena su komparativnom analizom numeričkih i eksperimentalnih studija procesa lansiranja UAV-a s lansera koji je dopustio verifikaciju ključnih parametara analiziranih sila.

\section{KEY WORDS}

physical modelling magnetic UAV catapult passive magnetic suspensions levitation forces

\section{INTRODUCTION / Uvod}

The navy became interested in magnetic catapults during the Second World War. At that time, Westinghouse built the first aircraft launcher system based on electromagnetic interactions
[12]. The devices called electropults were not commercialized, due to the high production and maintenance costs as well as heavy weight, and electromagnetic technology was supplanted 
bysteamlaunchers. In thelast twentyyears, theincrease in technology and progressive miniaturization has allowed the construction of cheaper and smaller devices, which makes the dimensions and operating costs of the newly designed electromagnetic launchers similar to the currently used steam launchers.

In 2000, the US Navy signed a contract with General Atomic for the design and construction of the EMALS (Electromagnetic Aircraft Launch System) prototype to replace the C-13 steam launchers. In July 2017, the system was successfully tested at sea on the aircraft carrier USS "Gerald R. Ford" [2]. An alternative design of an electromagnetic launcher with the acronym EMCAT (Electromagnetic Catapult) is being implemented in Great Britain [1], and analogous research is conducted in China and Russia. The NASA space agency [6] plans to use electromagnetic launchers to launch spacecraft and hypersonic aircraft.

The subject of the presented analyzes is the innovative prototype of GABRIEL launcher (Fig. 1), which uses levitation of diamagnetic materials in the magnetic field $[7,10,11]$. The launcher prototype was created as part of a project implemented in the 7th Framework Program of the European Union in 2011-2014. Due to the magnetic interactions used in the suspension construction of the launcher the friction between the starting cart and the generating the magnetic field by the tracks [3] was eliminated.

The tests of automatic landing and takeoff of the UAV [4] have shown that 20-meter magnetic tracks provide sufficient runway for the take-off and landing of a few kilograms UAV. This is a very important advantage and GABRIEL is the first system that has this property. During the research, however, a number of problems were observed resulting from mutual coupling between individual elements of the system, which motivated the following analyzes.

\section{ASSUMPTIONS OF THE PHYSICAL MODEL / Pretpostavka fizičkoga modela}

In order to describe the analyzed system of the magnetic launcher and its surroundings, the assumptions of the physical model have been formulated, taking into account its features, which have a decisive influence on the take-off and landing process of the BSP from the launcher. The launcher was modeled as a configuration of three elements.

1. the base of the launcher, along with magnetic fields generated by tracks glued with permanent magnets;

2. a starting cart, driven by a linear engine and hovering over the tracks as a result of the Meissner phenomenon;

3. unmanned aircraft taking off / landing on the launcher cart. Considering the couplings resulting from mutual interactions of particular elements of the system, the following assumptions were adopted, regarding the characteristics of the environment, external influences, kinematic constraints and the structure of the system elements.

Track system - starting cart (Fig. 2):

the launcher is located at sea level;

position and orientation of the launcher base remain unchanged during take-off;

the magnetic field generated by the left and right track rails is identical - there is symmetry relative to the longitudinal track axis;

fluctuations in the magnetic field due to the contact of magnets with the same polarity are neglected;

the starting cart is modeled as a rigid body with six degrees of freedom;

the weight of the cart, the position of the center of mass and the inertia tensor, described in the local system, remain constant;

superconductors are rigidly connected to the supports of the starting cart and cannot move or rotate inside them; the mass of evaporating from containers nitrogen is negligible;

- the dynamics of the starting cart is influenced by propulsion, gravitational and magnetic interactions;

the cart is not subject to aerodynamic effects;

the frame of the cart is made of non-magnetic material;

a linear motor, driving the cart, is modeled by a constant force, directed along the cart's movement;

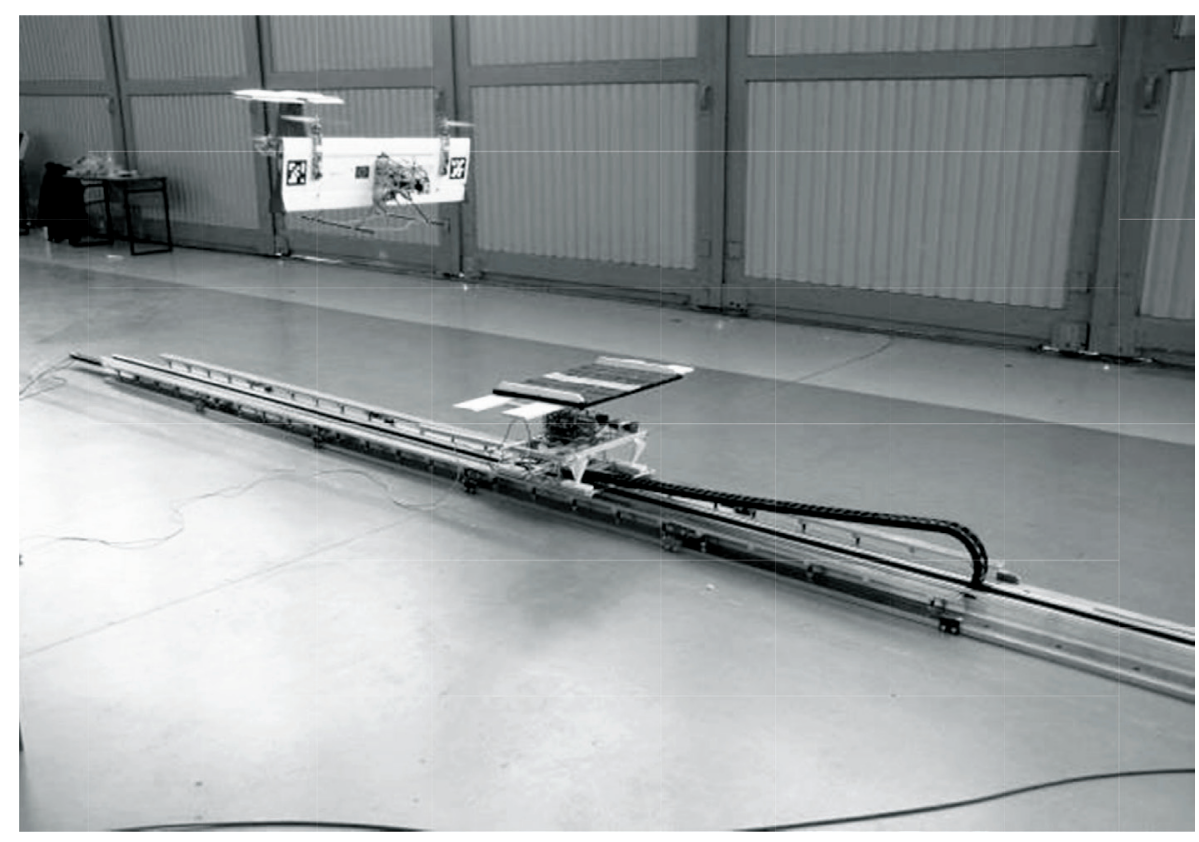

Figure $1 \mathrm{GABRIEL}$ launcher prototype during tests

Slika 1. GABRIEL prototip lansera za vrijeme testiranja 
- the force resulting from the displacement of the linear motor actuator, relative to the equilibrium point is acting on the cart in the direction perpendicular to the track.

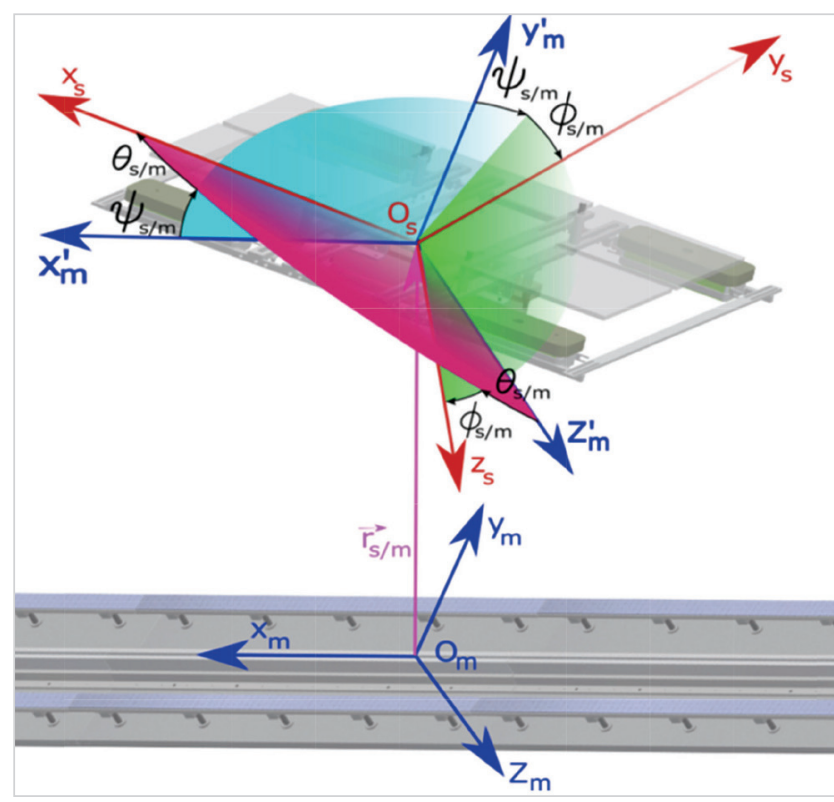

Figure 2 The orientation between the coordinate systems attached to the track and cart

Slika 2. Orijentacija između sustava koordinata dodana putanji i kolima

The starting trolley system - UAV (Fig. 3)

- the plane is modeled as a rigid body with six degrees of freedom;

- the mass of the airplane, the position of the center of mass and the inertia tensor, described in the local system, have a constant value;

- the take-off / landing of the aircraft takes place in a windless atmosphere;

- the density of air surrounding the aircraft depends on its height $\mathrm{H}$ and is determined in accordance with the relation $\rho=\rho_{0}\left(1-\frac{H}{44300}\right)^{4,256}$;

- the plane's motion is affected by forces and torques of gravity, propulsion, aerodynamic forces and reaction forces resulting from the contact of the airplane with the surface of the cart;

- during the take-off, before the moment of detachment, the plane is rigidly connected to the frame of the cart;

- the plane is made of non-magnetic material.

\section{COORDINATE SYSTEMS RELATED TO THE LAUNCHER ELEMENTS / Koordinatni sustavi koji se odnose na elemente lansera}

Each description of the motion of a mechanical object requires the establishment of reference systems. The movement of the object is described by means of coordinates and time in the event space. The location of the system elements is determined by linking the coordinate systems with them and determining their positions in a fixed coordinate system attached to the environment. Location of the object in space can be determined by specifying the time and six parameters defining spatial configuration, i.e. three linear coordinates defining the position and three angular coordinates defining the orientation.

The following rectangular right-handed cartesian systems are the basic reference systems used in the modeling process of the system: magnetic tracks - starting cart - aircraft:

- Fixed system $O_{f} x_{f} y_{f} z_{f}$ being an inertial system, rigidly connected to the ground (Fig. 4). The $O_{f} x_{f}$ and $O_{f} y_{f}$ axes of the system lie horizontally, with the direction of the $O_{f} x_{f}$ axis coinciding with the axis of symmetry of the launcher tracks, and its return is consistent with the movement of the runway, while the $O_{f} z_{f}$ axis is directed vertically downwards and its return is consistent with the return of acceleration Earth.

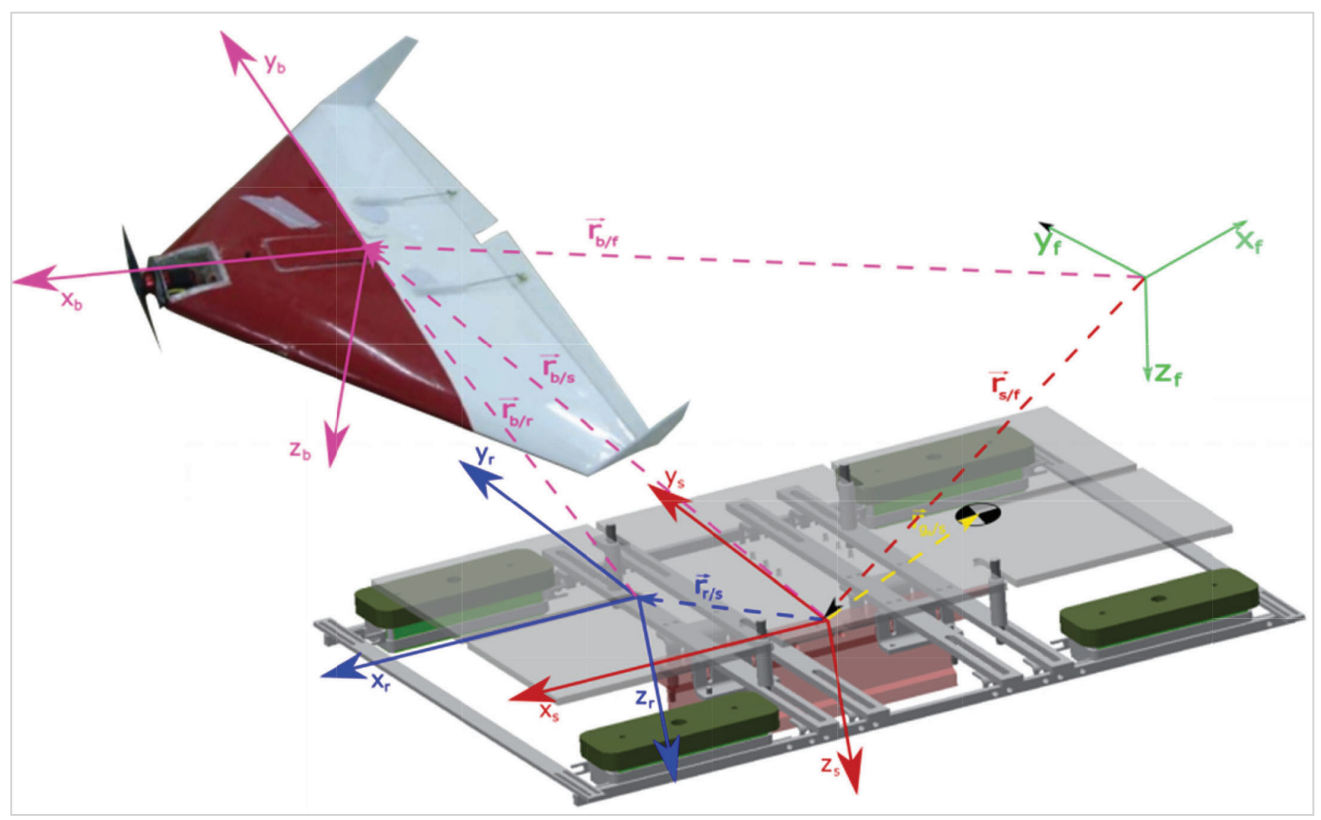

Figure 3 The orientation between the coordinate systems attached to the cart and UAV Slika 3. Orijentacija između sustava kordinata primijenjena na kola i UAV 


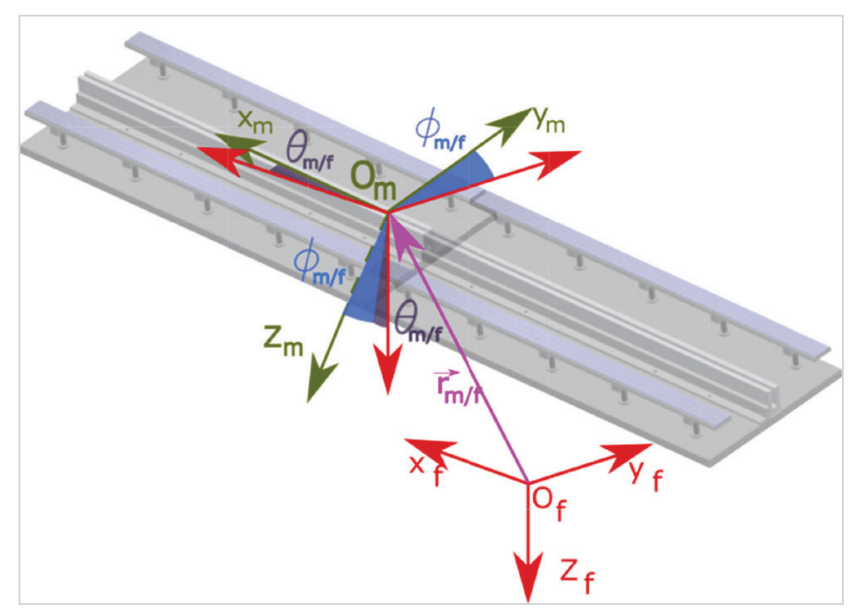

Figure 4 Location of the fixed system (inertial) and magnetic track system

Slika 4. Lociranje fiksnoga sustava (inercijalnoga) i sustav magnetske trase

- Magnetic track system $O_{m} x_{m} y_{m} z_{m}$ (Fig. 4), in which the distribution of the magnetic field lines is modeled. In the system are described the levitation forces acting on superconductors placed in the supports of the cart. The origin of the system is a projection of the geometrical center of the cart on the track's symmetry axis. The $O_{m} x_{m}$ axis coincides with the axis of symmetry of the launcher tracks, and its turn is compatible with the movement of the starting cart, while the $O_{m} z_{m}$ axis is directed perpendicular to the launcher base.

The orientation of the magnetic system, relative to the inertial system, is described by three independent angles: $\phi_{m / f}, \theta_{m / f}, \psi_{m / f}$ (Fig. 4). In order to simplify the model, it was assumed that the base system is selected so that the $O_{f} x_{f}$ axis coincides with the horizontal projection of the aircraft's direction of movement, i.e. $\psi_{m / f}=0 .^{\cdot} \theta_{m / f}$ !by simplifying the description of the magnetic system orientation to the two angles: $\theta_{m / f}$ and $\phi_{m / f}$ being respectively the rotation around the axis $O_{m} y_{m}$ and $O_{m} z_{m}$. The angle $\theta_{m / f}$ corresponds to the angle of inclination of the launcher relative to the ground, while the angle $\phi_{m / f}$ describes the degree of tilting of the launcher.

- Cart system $O_{s} x_{s} y_{s} z_{s}$ (Fig. 2) rigidly connected to the launcher starting cart. The origin of the system is a geometrical cart center, located at an equal distance from the four supports of the cart, the $O_{s} x_{s}$ axis is located along the longitudinal symmetry axis of the cart, the $O_{s} y_{s}$ axis connects the left and right support of the trolley containing superconductors, and the axis of $O_{s} z_{s}$ is perpendicular to the surface of the cart and completes the right-handed coordinate system.

The distance between the point of attachment of the $O_{s} x_{s} y_{s} z_{s}$ system and the origin of the magnetic system $o_{m} x_{m} y_{m} z_{m}$ is described by the vector $\vec{r}_{s / m}$. The orientation of the cart in relation to the magnetic system (Fig. 2) is described by angles $\phi_{s / m}, \theta_{s / m}, \psi_{s / m}$.

- Cart's gravitational system $O_{g s} x_{g g} y_{g s} z_{s g}$ is associated with the cart's mass center, which in general case does not have to coincide with the geometrical center. The displacement of the cart's mass center $\vec{r}_{g s / s}$ (Fig. 5) may result from deliberate change of mass distribution or imperfections of its structure (eg. heterogeneous mass distribution of the cart's frame structure, influence of displacement of the carts supply cable or non-uniform vaporization of liquid nitrogen from each of the trolley supports). The axes of the system are parallel to the inertial system.

Reaction system $O_{r} x_{r} y_{r} z_{r^{\prime}}$ in which the interaction forces between the starting cart and the airplane are described (Fig. 9). The system is parallel to the $O_{s} x_{s} y_{s} z_{s}$ cart system and its origin is determined by the point of contact between the plane and the surface of the cart. The distance between the cart system and the reaction system at the initial moment of landing is marked with the vector $\vec{r}_{r / s(0) \text {. }}$

UAV system $O_{b} x_{b} y_{b} z_{b}$ is rigidly connected with the airplane (Fig. 3). The origin of the system is located in $25 \%$ of the aerodynamic chord, the $O_{b} x_{b}$ axis coincides with the average aerodynamic chord, the $O_{b} y_{b}$ axis is parallel to the wings surface, and the $O_{b} z_{b}$ axis pointing down completes the right-handed coordinate system.

The vector connecting the beginning of the $O_{b} x_{b} y_{b} z_{b}$ system with $O_{r} x_{r} y_{r} z_{r}$ was marked with $\vec{r}_{b / r}$, while the vector connecting the center of the airplane's mass with the geometric center of the cart is the sum of the vectors $\vec{r}_{b / s}=\vec{r}_{b / r}+\vec{r}_{r / s}$. The orientation of the aircraft in relation to the inertial system is described by the angles $\phi_{b / f}, \theta_{b / f}, \psi_{b / f}$.

UAV gravitational system $O_{g b} x_{g b} y_{g b} z_{g b}$ is parallel to the inertial system, and its origin is located in the mass center of the aircraft

The vector connecting the beginning of the $O_{g b} x_{g b} y_{g b}$ $z_{g h}$ system from $O_{b} x_{b} y_{b} z_{b}$ has been marked with the symbol $\vec{r}_{g b / b}$ (Fig. 5).

Aerodynamic system of the airplane $O_{a} x_{a} y_{a} z_{a}$ is related to the direction of the velocity of the aircraft's flow (Fig. 8). The $O_{a} x_{a}$ axis coincides with the vector of the absolute speed of the aircraft, and the origin of the system is in the middle of the aerodynamics pressure.

Orientation of the $O_{a} x_{a} y_{a} z_{a}$ system with respect to $O_{b} x_{b} y_{b} z_{b}$ is described by the angle of attack $a$ and the angle of the slip $\beta$. Aerodynamic interactions are described in this coordinate system.

\section{FORCES AND TORQUES ACTING ON THE ELEMENTS OF THE MAGNETIC LAUNCHER / Sile i zakretni momenti koji djeluju na elemente magnetskoga lansera}

The loads acting on the launcher system result from dynamics and magnetic interactions acting on the cart as well as forces acting on the located on the cart UAV. In the presented notation of forces and torques, the upper vector represents the coordinate system, in which the vector has been described.

All elements of the magnetic launcher system are coupled by starting cart. The movement of the cart results from gravitational interactions, linear motor drive, magnetic levitation forces and - in the case when the starting trolley is associated with the airplane - forces of interaction between the plane and the trolley frame. Therefore, the force vectors $\vec{F}_{(s)}^{s}$ and the moments of forces $\vec{M}_{(s)}^{s}$ acting on the starting trolley are described by the following relationships:

$$
\begin{gathered}
\vec{F}_{(s)}^{s}=\vec{F}_{(G s)}^{s}+\vec{F}_{(L s)}^{s}+\vec{F}_{(N s)}^{s}+\vec{F}_{(r)}^{s} \\
\vec{M}_{(s)}^{s}=\vec{M}_{(G s) s}^{s}+\vec{M}_{(L s) s}^{s}+\vec{M}_{(r) s}^{s}
\end{gathered}
$$

where: $\vec{F}_{(G S)}^{s}, \vec{M}_{(G s) s}^{s}$ - gravitational forces and torques acting on 
the cart; $\vec{F}_{(L s)}^{s}, \vec{M}_{(L s) s}^{s}$ - magnetic levitation forces and torques; $\vec{F}_{(N s)}^{s}$ - propulsion of the linear drive; $\vec{F}_{(r)}^{s}, \vec{M}_{(r) s}^{s}$ - reaction forces and torques between cart and UAV.

The movement of the UAV is influenced by the force of gravity, aerodynamic impact, propulsion and reaction forces in the area of contact between UAV and cart:

$$
\begin{aligned}
& \vec{F}_{(b)}^{b}=\vec{F}_{(G b)}^{b}+\vec{F}_{(N b)}^{b}+\vec{F}_{(A b)}^{b}+\vec{F}_{(r)}^{b} \\
& \vec{M}_{(b)}^{b}=\vec{M}_{(G b) b}^{b}+\vec{M}_{(A b) b}^{b}+\vec{M}_{(r) b}^{b}
\end{aligned}
$$

where: $\vec{F}_{(G b),}^{b} \vec{M}_{(G b) b}^{b}$ - gravitational forces and torques acting on the UAV; $\vec{F}_{(N b}^{b}$ - propulsion of the UAV; $\vec{F}_{(A b)^{\prime}}^{b} \vec{M}_{(A b) b}^{b}$ aerodynamic forces and torques; $\vec{F}_{(r)}^{b}, \vec{M}_{(r) b}^{b}$ - reaction forces and torques between cart and UAV.

\subsection{Gravitational forces and torques / Gravitacijske sile i zakretni momenti}

The starting cart and the airplane are operating in the field of gravitational interactions. The developed model assumes, that the location of the mass center of the cart and aircraft does not have to coincide with the origin of the coordinate systems related to them. The vector of the gravitational force of the cart, designated $\vec{F}_{(G b)}$ is shown in Fig. 5a. while Fig. 5b. shows the vector of gravitational force $\vec{F}_{(G S)}$ acting on the UAV. The displacement of the mass center, relative to the $O_{s} x_{s} y_{s} z_{s}$ system, implies a non-zero moment from the gravitational forces $\vec{M}_{(G s) b}$ and $\vec{M}_{(G s) s}$.

\subsection{Propulsion / Propulzija}

The starting cart of the launcher is powered by an electric linear motor. The model assumes that the linear motor generates the resultant force $\vec{F}_{(N S)}$, with components lying in the $O_{m} z_{m}$ plane of the $O_{m} x_{m} y_{m} z_{m}$ system associated with the trolley (Fig. 6a). The desired driving force of the cart is described by the function $N_{s}$ and is directed along the longitudinal axis of the $O_{m} x_{m}$ magnetic system. The second component of the force generated by the linear motor is directed perpendicularly to the launcher and stabilizes the vertical position of the cart. The force $\left\{F_{(N s)}\right\}_{z_{m}}$ is modeled as a linear spring, and its value depends on the distance of the motor actuator $\left\{r_{s / m}\right\}_{z_{m}}$ from the equilibrium position $h_{0}$. Due to the lack of data, the model omits the component of the propelling force acting along the axis of $O_{s} y_{m}$ and all torques.

The driving force of the starting cart is described by the equation:

$$
F_{(N S)}^{s}=R_{m}^{s}\left[\begin{array}{c}
N_{s} \\
0 \\
k_{N s}\left(\left\{r_{s / m}\right\}_{z_{m}}-h_{0}\right)
\end{array}\right]
$$

where $R_{m}^{S}$ is a rotation matrix that maps the vectors described in the magnetic system $O_{m} x_{m} y_{m} z_{m}$ to the vectors described in the carts system $O_{s} x_{s} y_{s} z_{s}$, while $k_{N s}$ is a constant of elastic coefficient.

In the model adopted in the work, a BELL540 aircraft from BULLIT was used as a test plane [5] (fig. 6). It was assumed that the propulsion force of the aircraft has an unchanging direction, and its value changes in a linear manner. The plane is propelled

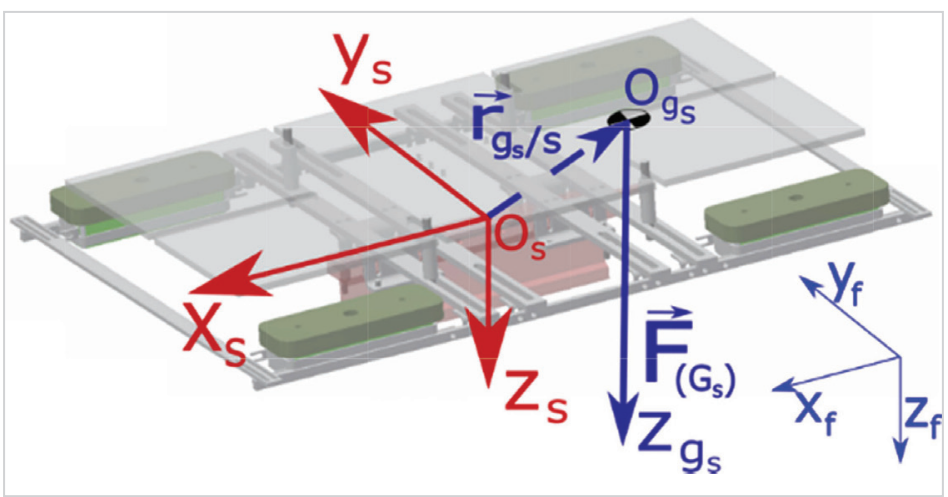

a)

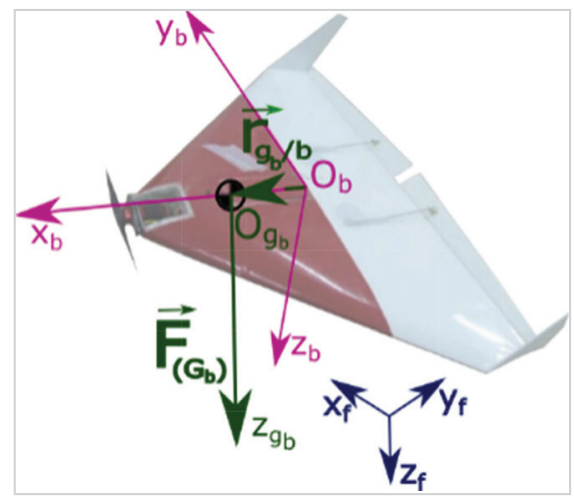

b)

Figure 5 The force of gravity acting on a) starting cart and b) UAV Slika 5. Sila gravitacije koja djeluje na a) polazišna kola i b) UAV

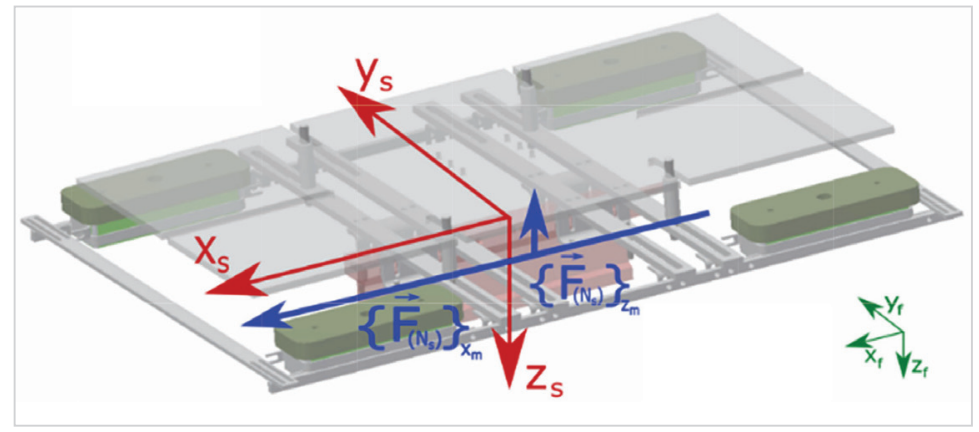

a)

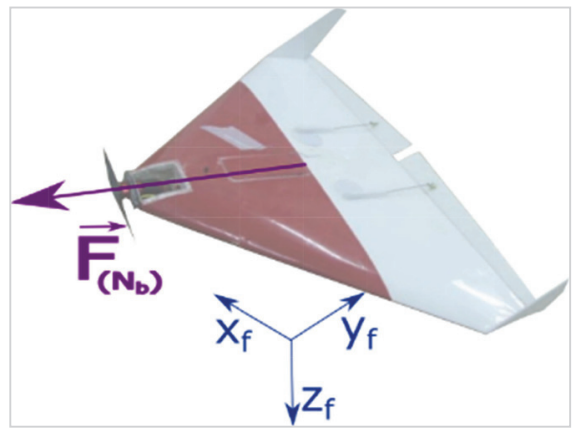

b)

Figure 6 The propulsion of the drive acting on the a) cart and b) UAV Slika 6. Propulzija poriva koji djeluje na a) kola i b) UAV 
by an electric motor located on the bow, Fig. $5 b$. Therefore, the propulsion force of the airplane $\vec{F}_{(N b)}$ is directed along the longitudinal axis of the $x_{b}$ plane of symmetry, and its value is described by the function $N_{b}$.

$$
F_{(N b)}^{b}=\left[\begin{array}{c}
N_{b} \\
0 \\
0
\end{array}\right]
$$

In the model, it was assumed that the axis of $O_{b} x_{b}$ rotation of the engine coincides with the axis of of the system, associated with the body of the aircraft, therefore the moment from the propulsive force is zero.

\subsection{Levitation forces and torques / Levitacijske sile $i$ zakretni momenti}

The value of the levitation force and torque depends on the intensity and direction of the magnetic field at a given point in the space and the position and orientation of the levitating superconductors $[8,9]$. On the superconductors lying inside of the carts supports acts the levitation force resulting from the Meissner effect $\vec{F}_{(L M)}$, directed perpendicular to the tracks.

However in case when superconductor was flooded with liquid nitrogen in a non-zero magnetic field, the proposed model takes into account also the magnetic interactions resulting from the magnetic flux trapping effect. The superconductor is then pushed by the force $\vec{F}_{(L F)}$ which attracts it to the center of the tracks. The force $\vec{F}_{(L F)}$ can be divided into two components: the first attracting the superconductor to the source of the magnetic field and pointing towards the axis $z_{m}$ and the second pushing the superconductor towards the center of the tracks, directed according to the $y_{m}$ axis.

If the superconductor is flooded with liquid nitrogen in a non-zero magnetic field, on the superconductor also acts the $\vec{M}_{(L F) O n}$, striving to set the superconductor's magnetic vector, according to the direction of the magnetic field, generated by the launcher tracks. The moment of force $\vec{M}_{(L F) O n}$ is calculated relative to the superconductors center.

The levitation force is weakly suppressed [3]. The damping value of the vertical vibrations of the cart is proportional to the vertical component of the cart's velocity and the experimentally tuned damping factor $c_{l}$. We assume that the model of damping is linear.

The forces and moments of forces acting on each of the four supports of the starting cart, are the resultant of all loads acting on all superconductors placed inside each support.

The resultant forces acting on supports are marked with symbols $\vec{F}_{(L P P)}$ (front right support), $\vec{F}_{(L P L)}$ (front left support), $\vec{F}_{(L T P)}$ (rear right support), $\vec{F}_{(L T L)}$ (rear left support). Analogous signs were used for the moments of levitation forces, counted around the support's centers of $O_{P P}, O_{P L}, O_{T P}, O_{T L}$ (Fig. 7).

For example, the levitation force $\vec{F}_{(L P P)}$ has the following components:

$$
F_{(L P P)}^{s}=R_{m}^{s}\left[\begin{array}{c}
0 \\
\left\{F_{(L F P P)}\right\}_{y m} \\
\left\{F_{(L F P P)}\right\}_{z m}-F_{(L M P P)}-c_{l}\left\{v_{s / f}^{(f)}\right\}_{z m}
\end{array}\right]
$$

where $\left\{F_{(L F P P)}\right\}_{y m}$ and $\left\{F_{(L F P P)}\right\}_{z m}$ are components of the levitation force resulting from the magnetic flux trapping effect acting on the front right support, whereas $F_{(L M P P)}$ is the levitation force resulting from the Meissner effect.

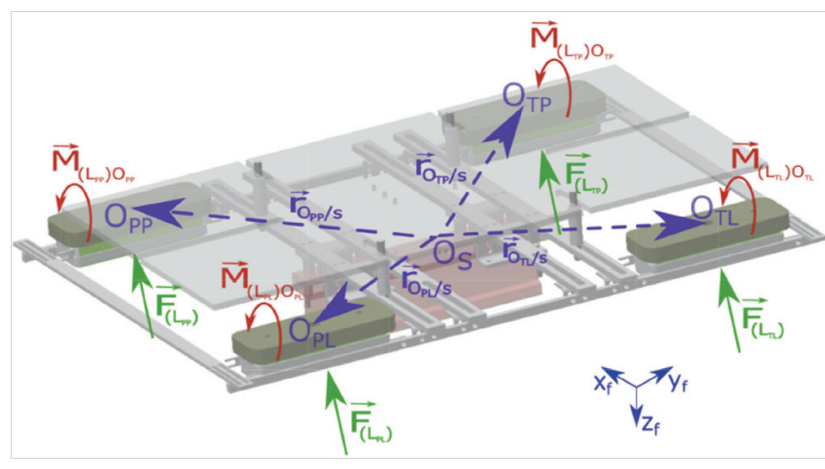

Figure 7 The levitation forces and torques acting on the supports of the starting cart

Slika 7. Levitacijske sile i zakretni momenti koji djeluju na podupiranje polazišnih kola

The remaining components of levitation force $\vec{F}_{(L P L)}, \vec{F}_{(L T P)}$, $\vec{F}_{(L T L)}$ can be divided into analogous components.

The resultant levitation force acting on the cart is the sum of the forces acting on its four supports:

$$
F_{(L S)}^{S}=F_{(L P P)}^{S}+F_{(L P L)}^{S}+F_{(L T P)}^{S}+F_{(L T L)}^{S}
$$

The developed model assumes, that the torque resulting from the flux trapping effect has only one non-zero component with respect to the $x_{m}$ axis, which for example for $\vec{M}_{(L P P)}$ is described by the dependence:

$$
M_{(L P P) O_{P P}}^{s}=R_{m}^{s}\left[\begin{array}{c}
\left\{M_{(L F P P) O_{P P}}\right\}_{s m} \\
0 \\
0
\end{array}\right]
$$

The resultant moment of levitation forces acting on the cart is the sum of moments of forces acting on the four supports of the trolley and the moment of the force being the vector product of the levitation force and the distance between points $\left(O_{P P}, O_{P L}, O_{T P}, O_{T L}\right)$ and the origin of the $O_{s} x_{s} y_{s} z_{s}$ system $M_{(L s) s}^{s}=M_{(L P P) O_{P P}}^{s}+s\left(r_{O P P / S}^{s}\right) F_{L P P}^{S}+M_{(L P L) O_{P L}}^{s}+$ $s\left(r_{O P L / S}^{S}\right) F_{L P L}^{S}+M_{(L T P) O_{T P}}^{S}+s\left(r_{O T P / S}^{S}\right) F_{L T P}^{S}+M_{(L T L) O_{T L}}^{S}+$ $s\left(r_{O T L / S}^{S}\right) F_{L T L}^{S}$

\subsection{Aerodynamic forces and torques / Aerodinamičke sile i zakretni momenti}

The value and direction of the aerodynamic force, acting on the aircraft depends on the flight speed, body surface and shape, the angle of attack $a$ and the density of the air at a given altitude. In the developed model, limiting the analysis to the longitudinal motion of the aircraft, the aerodynamic effects resulting from its lateral movements were omitted. Therefore, it was assumed that the aerodynamic impact is mainly influenced by the lift force $\left\{F_{(A b)}\right\}_{x_{a}}$, aerodynamic drag force na $\left\{F_{(A b)}\right\}_{z_{a}}$ (Fig. 8) and the pitching moment $\left\{M_{(A b) b}\right\}_{y_{a}}$.

The aerodynamic lifting and drag force is described in the aerodynamic system, associated with the air velocity vector. The transformation between the aerodynamic system and the local airplane system describes the angle of attack $a$ and the slip angle $\beta$.

The lifting force, directed perpendicular to the surface of the wing, allows the plane to fly. The value of the force is 


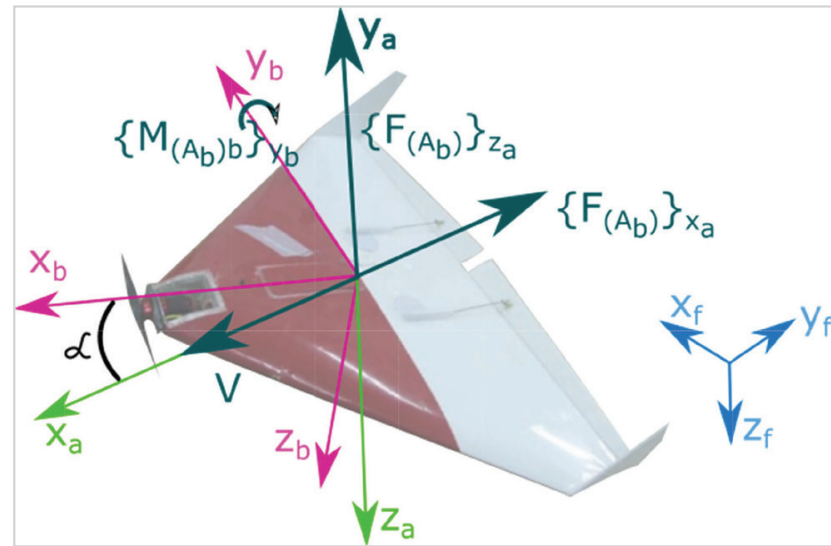

Figure 8 Aerodynamic forces and torques acting on the UAV Slika 8. Aerodinamičke sile koje djeluju na UAV

proportional to the wing reference surface $S$, the air density $\rho$ at a given altitude, the square of the aircraft velocity $v_{b / f}^{b(f)}$ and the aerodynamic coefficient $C_{L(\alpha)}$ dependent on the aerodynamic profile of the wing. As the velocity of the cart and laying on it airplane is rising, the lifting force increases until it balances the airplane weight. In the adopted model, the lifting force is determined based on the dependence

$$
L_{b}=\frac{1}{2} \rho S\left(\left(v_{b / f}^{b(f)}\right)^{T} v_{b / f}^{b(f)}\right) C_{L(\alpha)}
$$

During the longitudinal motion of the aircraft, the aerodynamic drag force plays a significant role. The direction of drag force coincides with the direction of the velocity vector, but its reverse is the opposite. In the developed model, the drag force is determined based on the equation

$$
D_{b}=\frac{1}{2} \rho S\left(\left(v_{b / f}^{b(f)}\right)^{T} v_{b / f}^{b(f)}\right) C_{D(\alpha)}
$$

where $C_{D(\alpha)}$ is a dimensionless coefficient of drag force. Values of coefficients $C_{D(\alpha)}$ i $C_{L(\alpha)}$ are determined experimentally on the basis of tests in the wind tunnel.

In this way, the resultant aerodynamic force is described by the following vector

$$
F_{(A b)}^{b}=R_{b}^{a}\left[\begin{array}{c}
-D_{b} \\
0 \\
-L_{b}
\end{array}\right]
$$

A tilting moment acts on the aircraft, causing the aircraft to rotate around its transverse axis. In the state of equilibrium, the moment of inclination is balanced by the moment of force resulting from the displacement of the mass center of the aircraft.

$$
M_{(A b) b}^{b}=\left[\begin{array}{c}
0 \\
M_{b}(\alpha) \\
0
\end{array}\right]
$$

The moment of the tilting force is determined in the model based on the dependence

$$
M_{b}=\frac{1}{2} \rho S\left(\left(v_{b / f}^{b(f)}\right)^{T} v_{b / f}^{b(f)}\right) l C_{m(\alpha)}
$$

where / is the wingspan and $C_{m(\alpha)}$ is the dimensionless coefficient of the moment of the inclination of the aircraft.

\subsection{Reaction forces and torques between the caty and the plane / Reakcijske sile i zakretni momenti između kola i lebdjelice}

Mutual interactions between the cart and the aircraft at the moment of take-off and landing are modeled in the form of a three-dimensional reaction force vector $\vec{F}_{(r)}$ and a three-element pseudo-reaction moment $\vec{M}_{(r) r}$ (Fig. 9).

During the UAV take-off from the cart it was assumed, that before the moment of detachment the plane and the cart are rigidly connected to each other, blocking the relative movement of the aircraft. Therefore, it was assumed that the UAV - cart system during the take-off has six degrees of freedom.

During landing, after the contact of the aircraft with the cart, the reaction forces $\vec{F}_{(r)}$ and torques $\vec{M}_{(r) r}$ act on the system elements. The reaction forces were modeled using a linear spring-damping element.

$$
\begin{gathered}
F_{(r)}^{S}=k_{r}\left(r_{r / s}^{S}-r_{r / s(0)}^{S}\right) c_{r l} v_{b / s}^{S(s)} \\
M_{(r) r}^{S}=-c_{r k} \omega_{b / s}^{S}
\end{gathered}
$$

The model allows to consider the relative movement of the aircraft after the touchdown moment, so the UAV - trolley system during landing has twelve degrees of freedom. The point at which the plane first encountered the surface of the starting cart determines the beginning of the $O_{r} x_{r} y_{r} z_{r}$. reaction system. The distance between the starting cart system and the reaction system at the initial landing moment was marked with the vector $\left.r_{r / s(0)}^{s}\right)$. As a result of the deformation of the platform on which the plane lands, the distance between the cart and the reaction system changes. The forces and moments of reaction

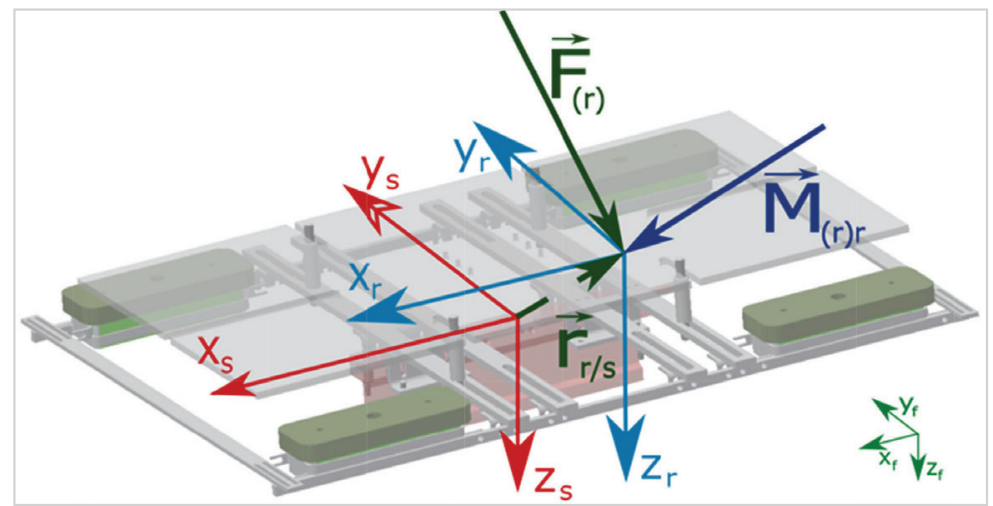

a)

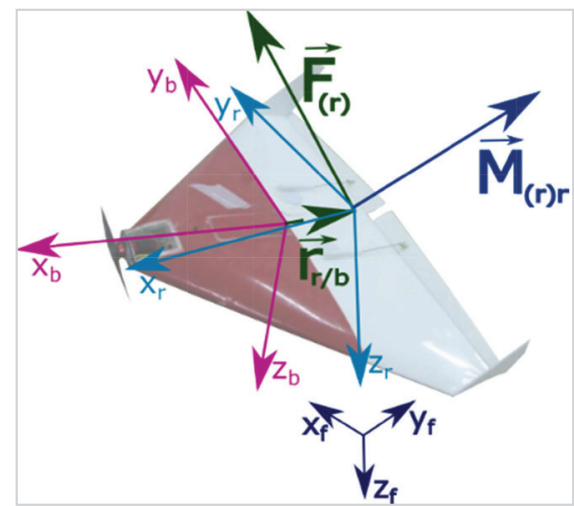

b)

Figure 9. Reaction forces and torques acting on a) UAV and b) cart Slika 9. Reakcijske sile i zakretni momenti koji djeluju na a) UAV i b) kola 


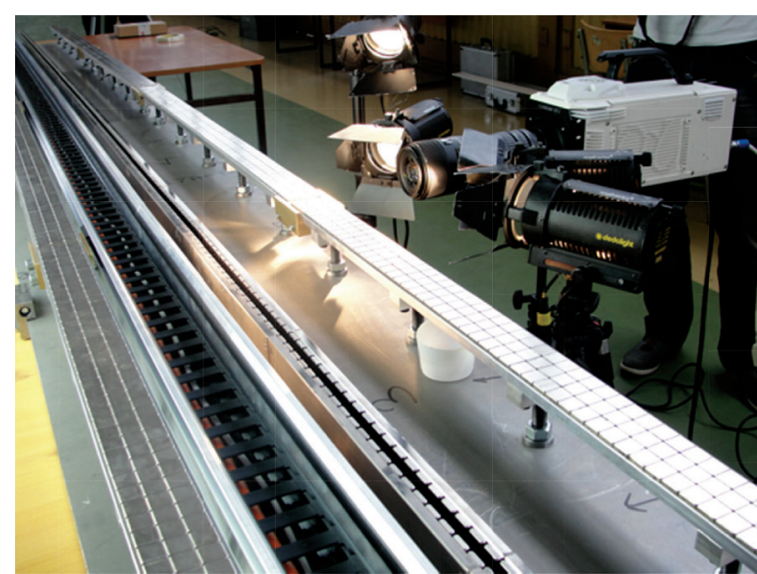

a)

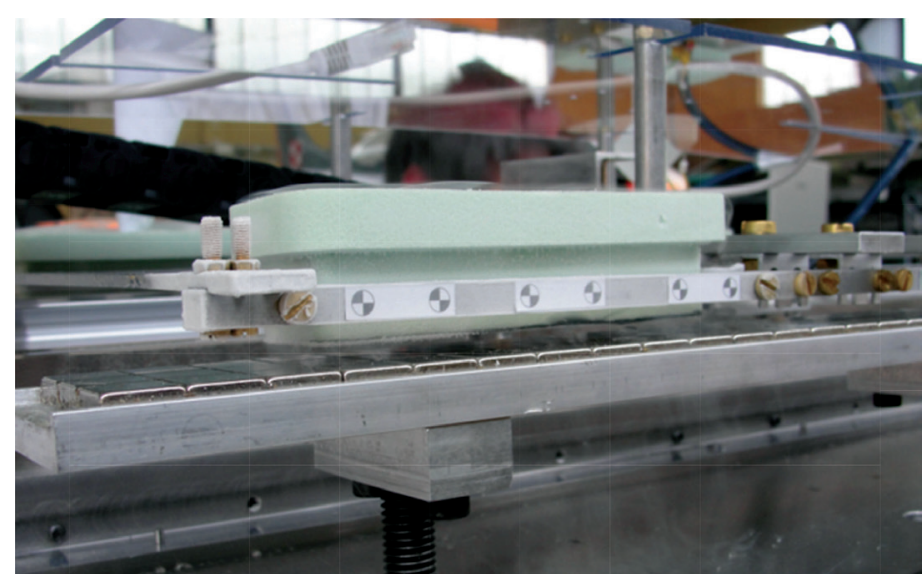

b)

Figure 10 a) MEMRECAM HX-5 camera recording trolleys vibrations b) trolley with markers Slika 10. a) MEMRECAM HX-5 kamera koja bilježi vibracije troleja b) trolej s markerima

forces are proportional to the change in the distance of the trolley from the beginning of the reaction system $\left(r_{r / s}^{s}-r_{r / s(0)}^{s}\right)$ and the relative velocity of the airplane $\vec{v}_{b / s}^{(s)}$ and $\vec{\omega}_{b / s}$.

\section{MODEL VERIFICATION / Verifikacija modela}

In order to verify the correctness of the developed model, data from the measurements of the magnetic suspension system obtained during the GABRIEL project were used $[4,11]$. Figure 10 shows the equipment used during experiments. A special overgoundmeasuring system consisting of the MEMREACAM HX-5 high-speed camera was developed, enabling recording of up to 6340 frames per second, with a resolution of 1 megapixels, optical distance sensor (ODSL 30/D232-30M-S12), a inertial sensor XSENSE MTi-300 HRS, a NI sbRIO-9633 Embedded Device with analog I/O and DIO, LX25 FPGA6. The high-speed camera MEMREACAM HX recorded the scene that consisted moving trolley and railways. During measurements, special markers facilitating image recognition were put on the trolley support and the catapults railways. The height and the vertical velocity of the trolley were established by the processing of recorded images.

The collected measurement data was used to validate key parameters analyzed in the work of forces acting on the magnetic launcher system.

An analysis of the developed analytical model revealed that the vertical motions of the trolley depend on zm -components of the following forces:

gravitation (figure. 5) that depends on the trolley and UAV mass,

proportional to the levitation gap levitation force caused by Meissner effect (figure. 7),

damping of levitation force that depends on trolley velocity and $c_{l}$ coefficient, as shown in equation 7 ,

vertical force from propulsion system described by equation 5 that depends on $k_{N s}$ and equilibrium position $h_{0}$.

Numerical simulations were developed in MATLAB. Simulation results reflect the trolleys vibrations during UAV take off. The simulation assumed that the UAV BELL 540 [5] weighted $m_{b}=1,5[\mathrm{~kg}]$ and UAV weight loss occurred in a linear manner during $0.3[\mathrm{~s}]$. The parameters of the trolley were set as: mass $m_{s}=1,4049[\mathrm{~kg}]$, dimensions (length / width / height) $l_{s}=0,5[\mathrm{~m}]$, $d_{s}=0,37[\mathrm{~m}], h_{s}=0,025[\mathrm{~m}]$, moments of inertia: $l_{x}=0,02\left[\mathrm{kgm}^{2}\right]$, $l_{y}=0,0364\left[\mathrm{kgm}^{2}\right], l_{z}=0,1491\left[\mathrm{kgm}^{2}\right]$.

Charts shown in figure 11 are comparison of the results of numerical simulations and measurements. The magnitude of levitation gap is increasing as a result of decreasing load of taking off UAV. The shift of equilibrium position causes trolleys vibrations which were precisely reconstruct by computer simulation. The vibration period of the cart is about 0.07 [s] and is weakly damped. The following parameters were adopted in the simulation: damping coefficients of the levitation force $c_{l}=1\left[\frac{\mathrm{N}}{\mathrm{m}^{2}}\right]$ stiffness coefficient of vertical propulsion force $k_{N s}=\left[\frac{\mathrm{N}}{\mathrm{m}}\right]$ and the equilibrium position $h_{0}=6,6[\mathrm{~mm}]$.

Established parameters of the model will be used in subsequent numerical simulations during further analysis of the trolley dynamics for various take-off and landing conditions.

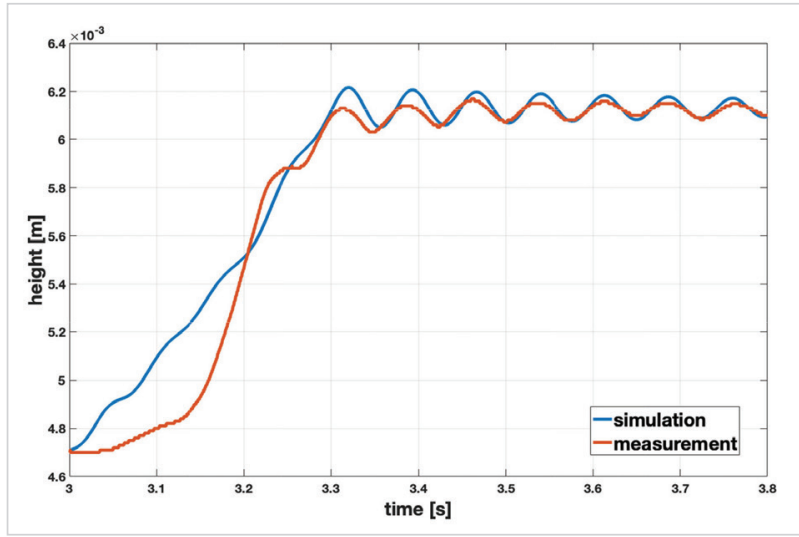

Figure 11 Comparison of measured and simulated vibrations of the trolley during take off

Slika 11. Usporedba izmjerenih i simuliranih vibracija na troleju za vrijeme polijetanja

\section{CONCLUSION / Zaključak}

The paper presents the developed of the physical model and theoretical analyzes the forces and torques acting on the launcher system. Considering the couplings resulting from mutual interactions of particular elements of the system, the set of crucial assumptions were adopted, regarding the characteristics of the environment, external influences, kinematic constraints and the structure of the system elements. This enabled the analysis of external interactions, that have a 
decisive impact on the dynamics of individual components of the launcher system: taking-off/landing UAV, the starting cart and generating magnetic field tracks.

In the analysis the special attention has been paid to the interactions of the forces and their impact on the take-off and landing process. This is important for the safe operation conditions of the launcher, due to the large values of forces and torques arising as a result of the interaction of the landing / taking-off UAV with the levitating cart and the magnetic tracks.

Theoretical considerations were supplemented with a comparative analysis of numerical and experimental studies of the UAV launch process from the launcher which allowed the verification of the key parameters of the analyzed forces. The determined parameters will be used during further analysis of the trolley dynamics during various conditions for take-off and landing and to develop an algorithm for controlling the trolley. This will enable precise alignment of the UAV while loading it on the launch truck. It is obvious that the biggest overloads are created at the time of UAV landing. Then, reaction forces act on the frame, which must be balanced by levitation forces and supporting forces from the linear motor, so that the cart does not fall out of the tracks. Reaction forces depend on the relative with the respect to cart angular and linear velocity. Therefore, adjusting the position and the velocity of the starting cart relative to the aircraft is critical to the safety of landing. This will be the next stage of ongoing work.

\section{Acknowledgements / Zahvale}

This study was supported by subsidy from financial resources for the maintenance and development of didactic and research potential granted for 2019 and the Warsaw University of Technology grant number 504/03821/1143/42.

\section{REFERENCES / Literatura}

[1] Fish T.: Cnverteam develops catapult launch system for UK carriers. Jane's Navy International, 2010, 115(7):8.

[2] LaGrone S.: "VIDEO: USS Gerald R. Ford Conducts First Arrested Landing, Catapult Launch". USNI News. U.S. Naval Institute, 28 July 2017 [accessed 2019 May 15] https://news.usni.org/2017/07/28/video-uss-gerald-r-fordconducts-first-arrested-landing-catapult-launch. https://doi.org/10.2 1236/ ad0013078

[3] Ładyżyńska-Kozdraś, E., Sibilska-Mroziewicz, A., Falkowski, K. Investigation of mechanical properties of a rigid body in magnetic levitation stat. Challenges of Modern Technology, 2015, 6(1), 23-27.

[4] Ładyżyńska-Kozdraś, E., Sibilska-Mroziewicz, A., Czubaj, S. K., Falkowski, K., Sibilski, K., \& Wróblewski, W.: Take-off and landing magnetic system for UAV carriers. Journal of Marine Engineering and Technology, 2017, 16(4), 298-304. https://doi.org/10.1080/20464177.2017.1369720

[5] Mystkowski A., Ostapkowicz P.: Weryfikacja modelu dynamicznego mikrosamolotu z wibrującymi generatorami wirów do sterowania przepływem. Prace Instytutu Lotnictwa, 2011, 103-125.

[6] Polzin K., Adwar J., Hallock A.: Optimization of electrodynamic energy transfer in coilguns with multiple, uncoupled stages. IEEE Transactions on Magnetics, 2013, 49(4):1453-1460. https://doi.org/10.1109/tmag.2012.2230271

[7] Rohacs D; Rohacs J.: Magnetic levitation assisted aircraft take-off and landing (feasibility study - GABRIEL concept), 2016, Prog Aerosp Sci. 85:33-50. https://doi.org/10.1016/j.paerosci.2016.06.001

[8] Sibilska-Mroziewicz, A., Ładyżyńska-Kozdraś, E., Falkowski, K., Wolski, K., Credo, W., Skalski, A. 2016. Experimental measurements of levitation force generated by high-temperature superconductors in magnetic field. W R. Jabłoński \& T. Březina, R. Jabłoński \& T. Březina (Red.), Advanced Mechatronics Solutions, 2016, ss. 255-260. Springer. https://doi.org/10.1007/978-3-31923923-1_38

[9] Sibilska-Mroziewicz, A., Czubaj, S. K., Ładyżyńska-Kozdraś, E., \& Sibilski, K.: The Use of Hall Effect Sensors in Magnetic Levitation Systems, Applied Mechanics and Materials, 2016, 817, 271-278. https://doi.org/10.4028/www.scientific. net/amm.817.271

[10] Sibilski K, Falkowski K.: Magnetic levitation system for take-off and landing airplane-project GABRIEL, COMSOL Conference, Rotterdam, 2013 [accessed 2019 May 14]. https:// www.comsol.fi/paper/download/182061/falkowski_ paper.pdf.

[11] Sibilska-Mroziewicz, A. Development of a dynamics model of an unmanned aircraft launcher, using the Meissner effect [in Polish], Phd Thesis 2018, Warsaw University of Technology

[12] Westinghouse Eng. A wound rotor motor 1400 feet long, Vol. 6, 1946, pages 160-161, [accessed 2019 May 15] https://www.theengineer.co.uk/october1946-westinghouse-unveils-the-electropult/ 